\title{
Integrating Facility Management Information into Building Information Modelling using COBie: Current Status and Future Directions
}

\author{
Laura Florez ${ }^{\mathrm{a}}$ and Kereshmeh Afsari ${ }^{\mathrm{b}}$ \\ ${ }^{a}$ Faculty of Engineering and Environment, Northumbria University, UK \\ ${ }^{b}$ School of Construction Management Technology, Purdue University, USA \\ E-mail: laura.florez@ northumbria.ac.uk, kafsari@ purdue.edu
}

\begin{abstract}
-
Building Information Modelling (BIM) has been implemented by architecture, engineering and construction (AEC) firms since it effectively manages and integrates information throughout the building life cycle bringing long term benefits compared to existing practices. BIM models serve as communication between design and construction phases. These models are used to determine geometry details, resolve constructability problems, track the types of materials, represent functional characteristics, and produce workflows among others. However, the benefits of BIM have not been fully extended to the operations and maintenance phase. Once the building is finished, the owner still needs the handover of paper documents to complete the information required to support the facility management phase. Therefore, to help owners extend information support throughout the building life cycle, this study proposes a process model to collect information required for facility management and incorporate it into BIM. A Construction Operations Building Information Exchange (COBie) approach is used to capture essential information to support facility management as it is created in design and construction. By capturing all the information, owners may be able to directly import data into maintenance management systems to support facility operations. Future directions are also discussed.
\end{abstract}

Keywords -

COBie; Facilities management; BIM; Integration

\section{Introduction}

Architects, contractors, consultants, and operators from many disciplines generate information in a variety of formats while designing and constructing a facility [1]. Once the facility is constructed, the information required for facility management is given to the owner for future operation, maintenance and decision-making. This information referred to as the as-built documents is compiled by the design team and is intended to show the actual location of systems and components in the building. However, the as-built documents are often poorly structured, missing, inaccessible or incomplete making it difficult for facility operators to locate necessary information and understand design objectives during their building operations tasks [1]. As-built documents should be planned to document the constructed state of a facility and reuse all the design and construction information as it is created to support facility management. To efficiently reuse all the information it is not only necessary to gather all the documents generated during design and construction, but to integrate them in a data set in order to support life-cycle operations and maintenance.

Relevant documents not incorporated in the data set and properly integrated may preclude equipment maintenance, preventive operations and other facility management goals. These goals may be achieved by considering the owner's requirements such as safe functional systems, life-cycle costs savings, extended equipment life, and reduction of unscheduled shutdowns and repairs [2]. The Computer-aided facility management (CAFM) is a widely applied approach used to support facilities management by information technology. CAFM systems track and maintain floor plans, building information, space usage, and occupancy data among others [10]. However, the value of these systems is limited since no party is assigned to update the data and information can only be distributed to facility management operators. The Computerized management maintenance system (CMMS) is a software package that upholds the information about the maintenance operations and schedules maintenance activities [3]. The CMMS improves uptime, establishes preventive maintenance, organizes work orders, help management make informed decisions, and allows data to be also useful when dealing with third parties. However, there is still some information essential for facility management that needs to be transcribed to be used for facility management since CMMS does not support related document linking. As a result, if a building wants to implement an effective management 
operations plan, the gathering and integration of data as it is created during design and construction is required.

The integration of information has been addressed by the integrated document management approach such as the Electronic Document Management Systems (EDMS) which is a very efficient approach to manage large numbers of documents in a systematic way [1, 4]. It has also been addressed by the model based approach defining data models such as Building Construction Core Model, Industry Foundation Classes and CADD/GIS data standards [1]. This approach is to produce documents automatically through query of an integrated representation and to communicate and exchange information across AEC disciplines.

There have been some practical changes and trials using BIM for better information transfer for facilities management. Recent developments have shown that after the completion of construction, many projects now require BIM-based documents for handover. For instance, efforts include FMie by buildingSMART [22], CAD technologies [13], building automation systems (BAS) [15]. Some countries have also mandated BIMbased documentation. In the UK, the government is pushing to implement BIM Level 3 by making mandatory that a data model can be accessed and modified in a single source (e.g. common data environment or open BIM) [21]. In the US, the requirement is a non-uniformed deliverable using a number of formats specified by the General Services Administration (GSA) [13].

However, the current procedure to integrate information lacks of a tool that helps decision makers organize knowledge on the various types of information generated during the building life-cycle to make reliable decisions and increase the life-cycle of the facility. An operational system design needs to be implemented if BIM is to integrate an effective design and support facilities management [12,21].Therefore, to help decision makers gather relevant information for facility management, this paper describes a process model to integrate information under a Construction Operations Building Information Exchange (COBie) approach. The process model describes the procedure to capture information and how to implement the COBie data set into a CMMS. In other words, the procedure traces information from its delivery by design and construction phases through its incorporation into the operations system and finally delivery to the owner. As the use of smart technologies is becoming more common in buildings, there is a need to transform FM data so that it can be integrated with smart devices. This needs changes both in the schema level of COBie and data translation effort so that the FM data can be exchanged through a network instead of just spreadsheets or IFC files. This paper discusses the process model to capture information and how to implement the COBie data sets and its future direction.

\section{Data requirements for facility management operations}

The Facility management and operations phase orderly controls activities required to keep a facility in an as-built condition while continuing to maintain its original productive capacity [3]. The objectives of this phase are to extend the useful life of assets, assure the optimum availability of equipment for production, ensure the safety of personnel using facilities, guarantee customer satisfaction, and provide healthy spaces $[1,2$, 3]. In order to comply with the objectives, facility managers must reuse effectively a wide scope of information created during design and construction by different parties to support operations and maintenance [1]. The information required to support facility management produced during the design phase includes material types, floor characteristics, building functions, floor plans and systems. Later, during the construction phase information required includes equipment lists, connections between equipment, product data sheets, warranties, preventive maintenance schedules, and submittal register among others $[1,2]$. Today, directives have been created to establish goals for reduction of energy and water consumption and to improve sustainability goals for both new and existing facilities $[12,13]$. These directives not only affect how facilities are designed and constructed but also how they will be operated and maintained $[2,10]$. The operations and maintenance activities will be guided to minimize operating costs while increasing occupant's productivity, improving energy performance, water consumption, indoor environmental quality and materials use [5]. As a result, other sources of data such as whole-building cleaning issues, waste stream water management programs, recycling programs, exterior maintenance programs, and systems upgrades will also be needed to perform facility management in buildings. New sustainability requirements affecting facility maintenance and operations include can be found in the Whole Building Design Guide [2] and the leadership in energy and environmental design (LEED) rating system for existing buildings operations \& maintenance (LEED-EBOM) [5]. Although the requirements and amount of information to operate and maintain a facility is increasing, facility managers lack of a tool to help them organize knowledge on the various types of information generated during the building life-cycle. The purpose of integrating information is to enable all the documents produced during the design and construction phases to be stored in a single integrated database $[1,4]$. The database contains the information 
generated in drawings and text documents. By accessing to the database, information on any particular building component can be retrieved and exchanged since data is standardized. In addition, information can be displayed in different formats allowing different parties to still use different software [2]. Representation of all the information needed to describe buildings throughout the whole design and construction process has been an objective for applying information technology (IT) in Buildings [6]. Informative case studies for BIM implementation for FM are detailed in [10-15, 18].

\section{Building information modelling and COBie overview}

The BIM is a tool for digital representation of physical and functional characteristics of a facility and it serves as a shared knowledge resource for information about a facility [7]. BIM represents real world elements as $3 \mathrm{D}$ objects. In addition to geometry details, other information is attached to these objects such as cost estimates, manufacturers, fire rating, and schedule among others [1, 4, 7]. Additionally, they have been used to solve constructability problems, conduct interference analysis and perform scheduling during the preconstruction phase [7]. These 3D models serve as a tool for communication between planning and design phases. However, BIM is rarely used during the post construction phase to address facility management issues $[1,7]$. A substantial amount of information is still collected and transferred to the owner in boxes. Therefore, an approach to data collection that is incorporated into a BIM model is required.

Data collection can be completed using a COBie approach. The COBie is an approach to enter data just as it is created during design, construction and commissioning $(\mathrm{Cx})$ phases. In other words, the information required by $\mathrm{COBie}$ is not different from the information already supplied in the design and construction contracts by all the parties. Since different parties use different software, they need to interact with COBie, as this information can be displayed in various formats [2]. All the formats provide an interoperable view of the underlying information specified by COBie and COBie can be customized to support specific requirements of an owner or a facility. Therefore, COBie allows having a one data set with different views enhancing the value of connection information and creating meaning since exchange is possible [2]. COBie's exchange specification is intended to transform existing deliverables into deliverables that contain the same information but in a new reusable format. COBie data includes spaces and zones of the facility, equipment and its location, submittals, instructions, tests, certificates, maintenance and safety protocols, start-up and shut-down procedure and resource data for the related activities [12]. Additionally, COBie data eliminates the reproduction cost for paper files, uses current software to deliver electronic handover information, ensures collaboration and integration of all project partners and improves the roll of construction submittals in construction handover $[2,7,11]$.

\section{Documentation process}

The COBie approach begins early in the design phase and goes through the commissioning phase (see Figure 1). The starting point of COBie is when the owner determines the objectives of the facility and states the requirements. Once the specific requirements are determined, the design phase starts. In the early design, the facility naming and the vertical and horizontal spaces that are needed are defined. Additionally, the different types of systems to satisfy the function of each space such as ventilation, mechanical, plumbing and electrical are also defined. COBie information in the design planning stage is provided via a listing of facility, number of floors, spaces in each floor, functions of spaces, and product and equipment types for each space. After the design planning stage information is provided, the information of the coordinated design such as name of equipment, equipment systems, space zoning, space layout, and location is provided. At last, the information of the final design stage is provided which includes design document register, as-designed equipment properties, product and data schedules and the equipment connection model.

After the design phase information input is completed, the construction phase information takes place. Builders provide not only the approved submittal documents but also all the information to complete the equipment data such as component systems, manufacturer, model, serial number and tag numbers. Later in the commissioning phase, job plans, warranty and parts documents and resources are also provided. Additionally, updates space functions and area measurements and operations and maintenance documents complete the commissioning documentation. As noted in Figure 1, the information integration is cumulative. In other words, the information is transferred from the early phases of the process to the late phases to improve decision-making. Therefore, COBie database gathers the accumulated information produced in each phase. For all of the information provided to be integrated into COBie, COBie specifications have to be followed within the existing contract specification [8]. This specification requires the handover of COBie information in the spreadsheet $\mathrm{XML}$ format at each phase. The COBie specification is 
implemented within the context of the existing specifications or performance based. Performance based specifications deliver information not as a stand-alone data, but as data that can be further incorporated to measure and quantify the building's performance [8]. Quantifying the building's performance enhances architectural design since the facility is measured in terms of the owner's specific requirements $[12,17]$.

\section{The integration approach}

The decision on how to create COBie data is based according to the firm's software and in many cases other firms are contracted to create it. COBie can be created using COBie compliant software, development of transformations of existing data into a COBie compliant file and direct use of the COBie spreadsheet $[8,13]$. Due to the variety of parties, a combination of these methods is usually followed to create the COBie deliverables. If the first method is used, the use of the software must be combined with manual configuration of the BIM software. This process can be performed using two different approaches. The first approach consists of producing a COBie file that complies with the buildingSMART international's facility management handover model view (MVD) definition specification for industry foundation classes (IFC) building information model (BIM) files [12].

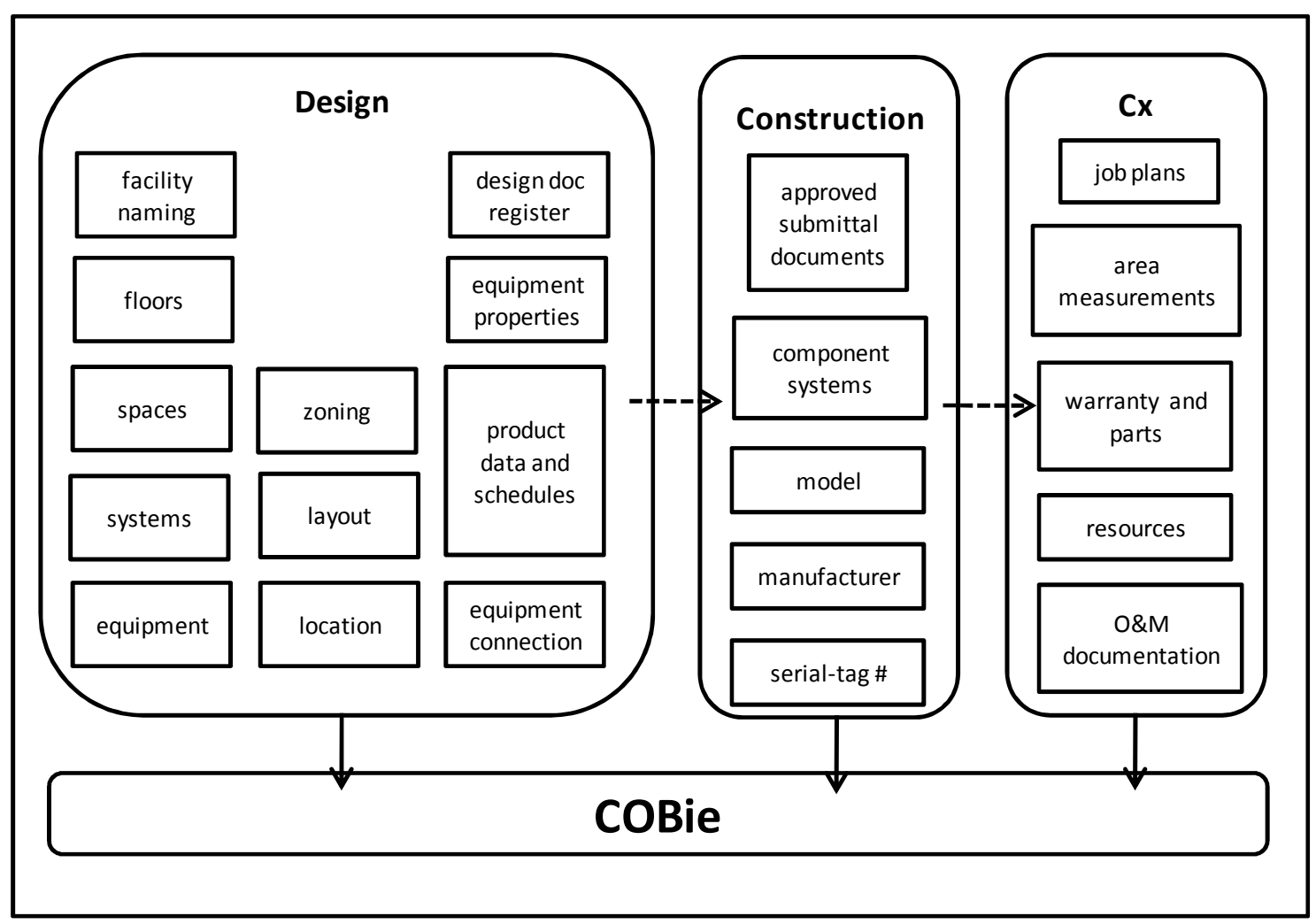

Figure 1. COBie approach. Adapted from WBDG, 2018. 


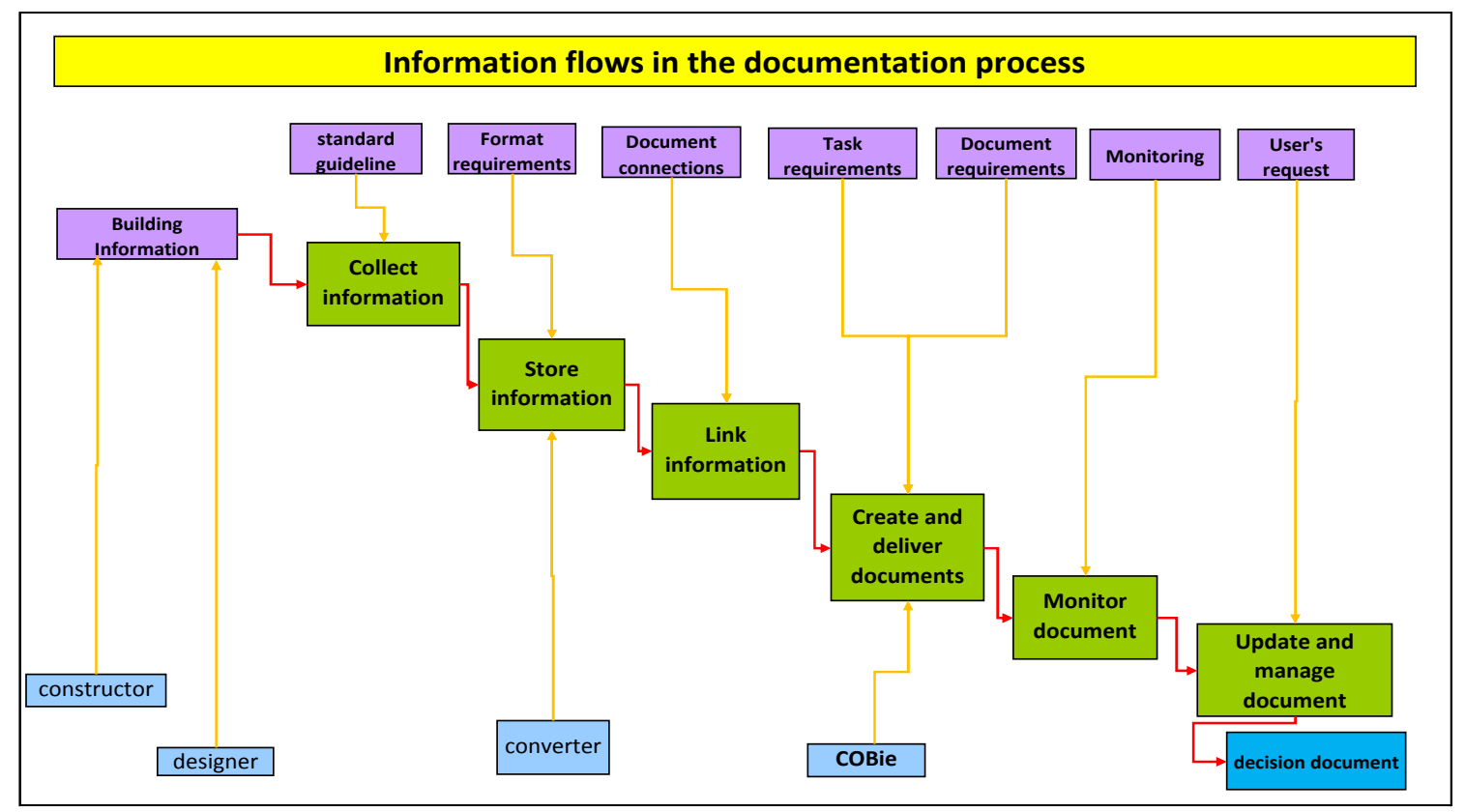

Figure 2. Adapted from Song et. al 2002

The COBie files produced have no technical difference with the MVD files, but to ensure compliance with the COBie contract language, the project parties must deliver the COBie formatted files. For that reason, a translation between the IFC files into a COBie formatted file is required [8]. The alternative approach needs the use of applications able of producing a file in the COBie spreadsheet format. The spreadsheet format of COBie is a modified version of Microsoft Excel spreadsheet which allows handling and saving of information as an Excel XML file format. As of December 2014, all software produced through the MVD will require some minimal manual adjustment to comply with COBie. Products from vendors who have completed COBie challenge can be found in the Whole Building Design Guide [2].

The second method to produce COBie files is based on capturing the information directly from the software tool in which it was created and the documents already containing the COBie information. For instance, applications containing equipment and room lists have most of the information required by COBie. For the case spreadsheets under a specific format are created, the spreadsheets' information is organized by hand or using other software. Afterwards, COBie information can be created using the exporting capabilities in the software. Finally, the third method is the input of the information in the COBie spreadsheet. By using this spreadsheet, the parties of the project can directly verify the accuracy of the information before submitting the COBie deliverable.
With all the information integrated into $\mathrm{COBie}$, the COBie data is completed and can be used to support the facility management operations. Figure 2 shows the information flow in the documentation process. The building information is the initial input. This information is later collected, stored and linked (using COBie). COBie deliverables are the monitor document and this data set needs to be updated and managed to become the decision document.

The process model framework shown in Figure 3 supports the decision maker in the process of facility management planning. The framework illustrates how the process of data integration is supported by using tools and software. In the data input module information is collected, in the integration module the interoperability procedure and integration of documents into COBie occurs using an integration model of heterogeneous databases, then in the standardization module the translator is checked for compliance and finally in the operation module the standard format document is given to the owner or decision maker.

Since COBie data can be directly imported into the CMMS, no further standardization is needed and the complete facility operation and maintenance plan can be effectively controlled using the CMMS.

The integration module is the main enabler of this process model. This module uses an XML schema mapping using ifcXML (XML-based data interoperability) for querying and integration of data from heterogeneous data sources containing facility operations and maintenance information. The ifcXML is 
an implementation of the ISO-10303 Part 28 Edition 2 standard that provides an XML schema specification of the IFC schema through an automatic conversion from the IFC EXPRESS (ISO 10303 part 1) representation [22]. The integration framework for heterogeneous data sources has been the center of many database studies and the XML-based integration model dealing with transformation of heterogeneous data has proven to be effective in many prior studies [23, 24, 25]. The ifcXML schema provides both IFC interoperability features and XML-based data integration capabilities. Using ifcXML schema, data from diverse sources such as design, construction, and commissioning stage will be integrated and maintained in an XML-based database following IFC data model and will then be configured and mapped to COBie dataset.

\section{Limits and benefits}

Implementation of the process model described may be successful if parties involved in construction rethink and reorganize the building process throughout its lifecycle. Collecting and storing information in the minimum required format to then integrate it into COBie format might require new responsibilities and costs. The process of capturing information may need new personnel and training. It may also need agreement among the owner and AEC parties in the procedures to be implemented.

BIM has the potential to change the way construction is performed and documented. The transition requires a complete shift through all the phases of the building's life-cycle. BIM could become the data source of information including facilities management $[16,19]$. The advantages of BIM include improvements in productivity as compared to other practices. Though, there are no reliable methods to measure the benefits of BIM and quantify the results of the new practices. Therefore, there may be some building participants who may still refuse to use BIM models and integrate information to improve the way construction is performed [17]. The process model described has demonstrated COBie data as a practical solution to the current problems of the as-built documents in order to support facility management. The benefits of using the process model include delivery of necessary and concise information, easy access to related information, enhanced collaboration between the parties, and provide reliability of information among others.

\section{Discussion and conclusions}

A number of studies on integration of information have been carried out, indicating the use of approaches to manage and compile facility operations and maintenance documents in a systematic way as well as models to integrate information and produce new formats. Although the integration of information has been approached by considering standards that may facilitate the input of information, the owner who is the final user of the format has not been considered. Owner's still receive information in boxes and have to gather and re-organize the information since it was usually produced by different parties using different software. In addition to the owner's need to translate information, the as-built documents are often poorly structured, missing, inaccessible or incomplete. Gathering this information is expensive and at the end is not a reliable database since it differs from the actual construction.

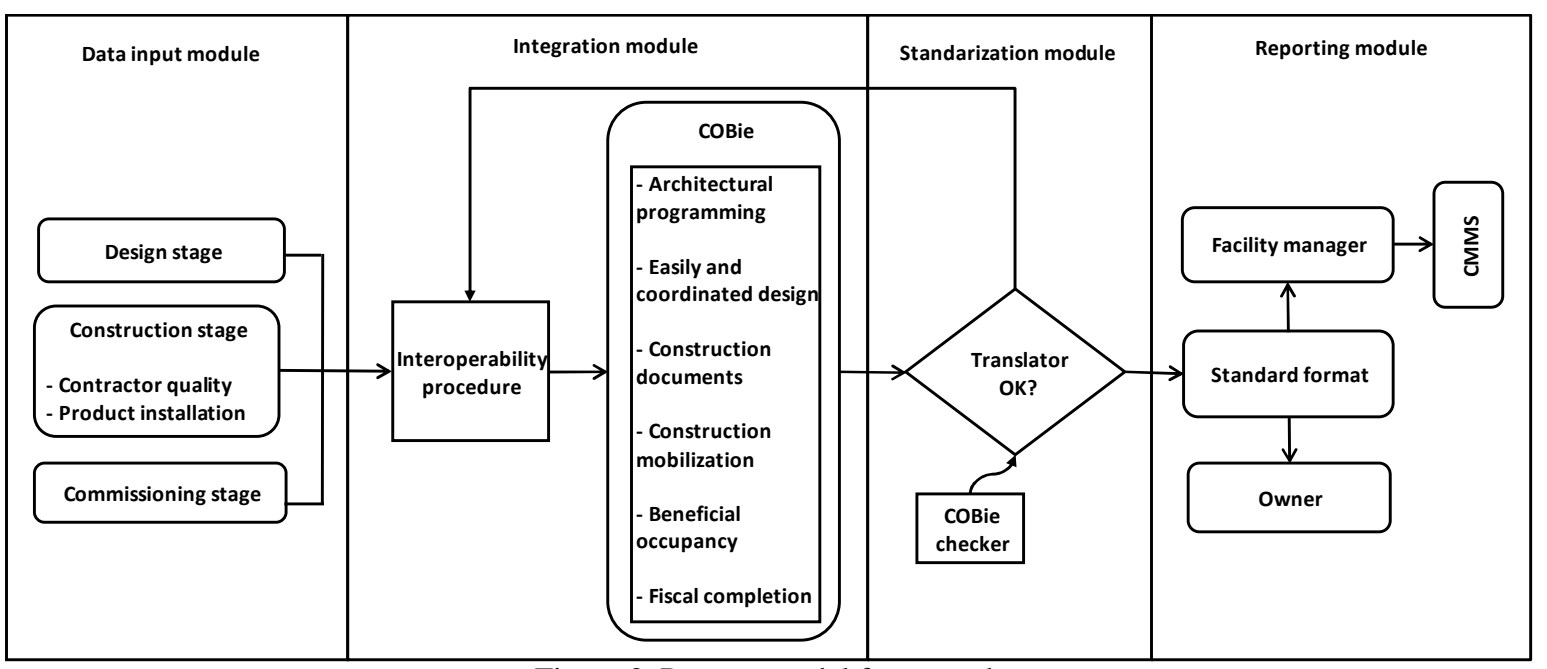

Figure 3. Process model framework 
Therefore, an integration approach is needed to help owners support facility management operations with reliable data. COBie data set was developed to deliver accurate information to the owner in a format that can be used for facilities management.

The process model framework described in this study can help gather information and bring significant positive changes to the actual process of facility operations and maintenance activities. Its usefulness lies in the opportunity to include in the integration process information just as it is created in the design and construction phases. The possibility for all the different parties to include information from different software and different formats may help improve the quality of the as-built documents. As-built documents can be created and intended to reuse efficiently design and construction information to support operations and maintenance. Through COBie standards and the welldeveloped software products available in the market to transform documents into COBie documents, the benefits of information integration of a building can be realized. As a result, the process of facility management may be simplified and accelerated. COBie data set may broaden the capabilities of the decision-making process by allowing owners and facility managers to efficiently use reliable data without needing to gather and translate information.

The applied process model incorporates all the information of a building relevant to support facility management operations. The information is then integrated through an interoperability procedure to convert it into COBie information. Afterwards, a COBie check is run to verify the translators work properly. Once the check is concluded, the deliverables of COBie are ready to be used by owners to assist decision making in facility management operations. The implementation of the proposed process map and application case for indicating the actual uses of this process map is a future study.

As electronic environments increase, the range of document formats expands overwhelming users with information and making the retrieving information process effortful. Therefore, it is necessary to understand the information integration tools in order to help users benefit from all the information provided and successfully implement it to accomplish their tasks. The process model described in this study may contribute to benefit the integration of information for facility management operations. By investigating the products available that have applications capable of producing the format needed by the final user, information databases could become valuable tools to assist in operations in an ever-expanding range of options. As the use of smart technologies is becoming more common in buildings, there is a need to transform FM data so that it can be integrated with smart devices. This needs changes both in the schema level of COBie and data translation effort so that the FM data can be exchanged through a network instead of just spreadsheets or IFC files [9, 17, 20]. The understanding of demand and needs within building construction enhance consumer satisfaction contributing on how to make practices remain viable and useful for the construction sector.

\section{References}

[1] Song, Y., Clayton M.J., and Johnson, R.E. Anticipating reuse: documenting buildings for operations using web technologies. Automation in Construction, 28(11), 185-197, 2002.

[2] WBDG (Whole Building Design Guide). Construction Operations Building Information Exchange (COBie)). https://www.wbdg.org Accessed 18/01/2018.

[3] Korka, J.W., Oloufa, A.A., and Thomas, R. Facilities computerized maintenance management systems. Journal of Architectural Engineering, 3(3), 118-123, 1997.

[4] Caldas, C.H.., Soibelman, L., and Gasser L. Methodology for the integration of project documents in model-based information systems. Journal of Computing in Civil Engineering, 19(1), 25-33, 2005.

[5] USGBC (United States Green Building Council). LEED for existing buildings operations \& maintenance (Reference Guide Version 2.0). Washington, D.C; 2008.

[6] Howard, R. and Bjork, BC. Building information modeling - Expert's views on standardization and industry deployment. Advanced Engineering Informatics, 22(4), 271-280, 2008.

[7] Goedert, J.D., and Meadati P. Integrating construction process documentation into Building Information Modeling. Journal of Computing in Civil Engineering, 134(7), 509-517, 2008.

[8] NIBS (National Institute of Building Sciences). Construction Operations Building Information Exchange (COBie): Means and Methods. BuildingSMART alliance. https://www.nibs.org Accessed 18/01/2018.

[9] Vanlande, R., Nicolle, C., and Cruz C. IFC and building lifecycle management. Automation in Construction, 18(3), 70-78, 2008.

[10] Yalcinkaya M., and Singh V. Building Information Modeling (BIM) for Facilities Management Literature Review and Future Needs. In: Fukuda S., Bernard A., Gurumoorthy B., Bouras A. (eds) 
Product Lifecycle Management for a Global Market. PLM. IFIP Advances in Information and Communication Technology, vol 442. Springer, Berlin, Heidelberg, 2014.

[11] Lavy, S., and Jawadekar, S. A Case Study of Using BIM and COBie for Facility Management. International Journal of Facility Management, 5(2), 2014

[12] Becerik-Gerber, B., Jazizadeh, F., Li, N., and Calis, G. Application areas and data requirements for BIM-enabled facilities management. Journal of construction engineering and management, 138(3), 431-442, 2011.

[13] Shen, W., Hao, Q., Mak, H., Neelamkavil, J., Xie, H. Dickinson, J., Thomas, R., Pardasani, A., and Xue, H. Systems integration and collaboration in architecture, engineering, construction, and facilities management: A review. Advanced Engineering Informatics, 24(2), 196-207, 2010.

[14] Wetzel, E.M., and Thabet, W.Y. The use of a BIM-based framework to support safe facility management processes. Automation in Construction 60(4), 12-24, 2015

[15] Kassem, M., Kelly, G., Dawood, N., Serginson, M., and Lockley, S. BIM in facilities management applications: a case study of a large university complex, Built Environment Project and Asset Management, (5)3, 261-277, 2015.

[16] Suprabhas, K., and Dib, H.N. Integration of BIM and Utility Sensor Data for Facilities Management ASCE International Workshop on Computing in Civil Engineering, 2017.

[17] Liu, R., and Issa, R.R.A. Issues in BIM for facility management from industry practitioners' perspectives, in: I. Brilakis, L. SangHyun, B. Becerik-Gerber (Eds.), ASCE Computing in Civil Engineering, pp. 411-418, 2013.

[18] Cavka, H.B., Staub-French, S. and Pottinger, R. Evaluating the alignment of organizational and project contexts for BIM adoption: a case study of a large owner organization, Buildings 5(4), 12651300, 2015.

[19] Terreno, S., Anumba, C.J., Gannon, E., and Dubler, C. The benefits of BIM integration with facilities management: a preliminary case study, Computing in Civil Engineering, 675-683, 2015.

[20] Afsari, K., Eastman, C., and Shelden, D. Cloudbased BIM Data Transmission: Current Status and Challenges. 33rd International Association for Automation and Robotics in Construction, 10991106, 2016.

[21] (BIM3A) BIM's third age. http://www.fmworld.co.uk/features/feature-articles/bims-thirdage/ Accessed 03/08/2018.

[22] Nisbet N., Liebich T. ifcXML Implementation
Guide, International Alliance for Interoperability (IAI) Modeling Support Group, 2007.

[23] Collins, S. R., Navathe, S., \& Mark, L. XML schema mappings for heterogeneous database access. Information and Software Technology, 44(4), 251-257, 2002.

[24] Gardarin, G., Mensch, A., Dang-Ngoc, T. T., \& Smit, L. Integrating heterogeneous data sources with XML and XQuery. In Database and Expert Systems Applications, 2002. Proceedings. 13th International Workshop on (pp. 839-844). IEEE, 2002.

[25] Nie, F. Y., Wu, F. F., \& Wan, L. Y. Study on Integration Model of Heterogeneous Database Based on XML Technology. In Advanced Materials Research (Vol. 912, pp. 1403-1406). Trans Tech Publications, 2014. 